\title{
Chimerism after organ transplantation
}

\author{
Thomas E. Starzl, Anthony J. Demetris, Noriko Murase, Massimo Trucco, Angus W. \\ Thomson, Abdul S. Rao, and John J. Fung \\ Pittsburgh Transplantation Institute and the Departments of Surgery, Pathology, and Pediatrics, \\ University of Pittsburgh Medical Center, Pittsburgh, Pennsylvania, USA
}

\section{Abstract}

Recent evidence suggests that passenger leukocytes migrate after organ transplantation and produce persistent chimerism, which is essential for sustained survival of the allograft. Here, we describe how this hematolymphopoietic chimerism provides an important framework for interpretation of posttransplant phenomena and for initiation of therapeutically oriented transplantation research.

\section{Introduction}

A link between bone marrow and organ transplantation was provided when microchimerism was detected with sensitive immunocytochemical and polymerase chain reaction techniques in the tissues or blood of 30 human kidney or liver recipients studied from 2.5 to 30 years postoperatively $[1,2]$. The donor cells were multilineage, but paradoxically many appeared to be dendritic cells (DCs), a potent antigen-presenting cell [3]. Individual samples from patients often do not contain the donor leukocytes, which wax and wane [4]. However, disseminated donor cells including DCs, or alternatively donor DNA, are consistently demonstrable if rodents bearing long-term grafts are thoroughly studied [5-7].

Along with peripheral migration of the donor cells from a successfully transplanted graft, there is an influx of host leukocytes that do not cause graft damage [2]. Thus, both the allograft and recipient become genetic composites (Fig. 1a). A mirror image condition exists after bone marrow transplantation [8] (Fig. 1b), proved by demonstrating a trace residual population of host leukocytes in essentially all stable human bone marrow recipients who previously were thought to have complete donor-cell chimerism [9].

\section{Previous enigmas}

These discoveries have provided an important framework for a better understanding of allograft 'acceptance', for analysis of management problems, and for therapeutically oriented transplantation research [10••]. In the new context of this two-way paradigm, the donor leukocytes in organ recipients constitute the small member of antagonistic but reciprocally attenuated or abrogated host-versus-graft (HVG) and graft-versus-host (GVH) arms, each of which can induce specific nonreactivity (tolerance) in the other [1,2,8] (Fig. 2). Deletion of the host arm by the cytoablation before bone marrow but not before organ transplantation alters the balance in this mutual interaction and is thus responsible for the disparities in the two different kinds of transplantation (Table 1).

\footnotetext{
(C) Rapid Science Publishers

Corresponding author: Thomas E. Starzl MD, 3601 Fifth Avenue, 4C Falk Clinic, Pittsburgh, PA 15213, USA.
} 
The dynamic 'nullification' effect of the two arms makes it obvious why kidney recipients can sometimes stop immunosuppression without losing their allografts [10••]. It also explains the poor prognostic value of human leukocyte antigen matching for organ transplantation, the rarity of GVH disease after the engraftment of immunologically active organs such as the intestine and liver, and the characteristic cycle of immunologic crisis and resolution, first observed in kidney recipients [11], that was most practically monitored by serial changes in organ allograft function (Fig. 2).

The two-way paradigm defines success and failure after transplantation in a different way than before. Success implies that chimerism has been introduced which may or may not be immunosuppression-dependent. Failure connotes the therapeutically uncontrollable ascendency of HVG or GVH. Pathologic evidence of both processes is frequently found in failed liver or intestinal transplant cases, but the ultimate result is predominantly rejection or GVH disease. In kidney recipients who are exposed to a small load of passenger leukocytes, findings in the recipient and allograft are essentially always interpreted in the context of rejection.

\section{The counter-argument}

In the previous conception of organ allograft acceptance, which excluded a role for lymphoid cell microchimerism, it was axiomatic that antigens of the parenchymal (or vascular endothelial) cells of transplanted organs permitted or induced allograft acceptance [12] in various ways, for example via veto/suppressor cells, cytokine profile changes or enhancing antibodies. In an extension of such reasoning, it has been contended that the microchimerism associated with successful organ transplantation, and conversely its disappearance with or just after irreversible rejection in experimental models [5,7], is inconsistent and epiphenomenal [13].

Such arguments have been skilfully summarized in a debate format by Wood and Sachs $[14 \bullet]$. However, there is no credible evidence to support the contention $[13,14 \bullet]$ that the microchimerism found in organ recipients is the effect rather than the cause of allograft acceptance. Failure with limited tissue or blood sampling to find peripheral microchimerism in patients after successful organ transplantation connotes an incomplete search [15]. In our clinical studies [1,2] in which sampling was from multiple sites, the inconsistent yields from individual locations were comparable with those reported by others [14•]. However, when the results were pooled from the different sites in individual cases, all 30 of our originally tested patients had microchimerism. In rat experiments where tissues can be retrieved without limit, we have achieved a consistent association of chimerism with avoidance of chronic rejection $[5-7,15]$.

\section{Post-transplant lymphoproliferative disorders}

The two-way paradigm also has shed light on the pathogenesis of post-transplant lymphoproliferative disorders (PTLDs) [16••]. Except for their frequent Epstein-Barr virus (EBV) association, these human B-cell lymphomas are indistinguishable from those induced by Schwartz et al. [17] in a mouse chimerism model 3 years before the PTLD complication was first recognized clinically [18] and explained by loss of surveillance [19]. Rather than simple loss of surveillance, Schwartz et al. ascribed the experimental tumors to an active lymphoproliferative response by the dominant immune apparatus to the persistent subclinical GVH counterattack of the minority donor leukocyte population. The relevance of his observations to clinical PTLDs could only be appreciated 30 years later with the discoveries of microchimerism. 
Now, it could be seen that PTLD is a complication of the joint activation of the coexisting immune populations, to which the powerful cofactors of immune suppression and viral infection (particularly with EBV [20]) are added [16••]. Because host leukocytes in most organ recipients vastly outnumber the chimeric donor cells, with a similar obverse disproportion in successfully engrafted bone marrow recipients, clinical PTLDs are usually of recipient origin in the first instance and of donor phenotype in the second (summarized in [16••]).

Heavy immunosuppression typically precedes the appearance of the tumors in the human organ recipient. Conversely, reduction or discontinuance of the antirejection drugs [21] can allow restoration of immune surveillance, manifested by PTLD regression. Tumor involution frequently is coincident with organ rejection, but in most cases a level of immune suppression can be reached by trial and error that permits salvage of the allograft without precipitating regrowth of the lymphoma [21-23].

This dissociation of lesion involution and rejection has suggested that the tumor destruction might be by an autologous immune reaction directed to a tumor-specific antigen and that the target was an EBV-infected immunoblast, freed from T-cell surveillance by immunosuppression [24-27]. However, this does not explain why the less common $\mathrm{EBV}^{-}$ neoplasms also often frequently regress when immunosuppression is stopped [16••]. Thus, although viral cofactors, and especially EBV, are undoubtedly involved in the development of PTLD, their role has not been fully clarified.

Nevertheless, fresh insight about PTLD obtained so far can be used to map treatment strategies of cellular immune modulation as discussed elsewhere [16••]. How to prevent PTLD is also obvious. Because immune suppression is a dominant cofactor, particularly when it is T-cell directed, it was not surprising to note an incremental increase in PTLD with successively more potent immunosuppressants $[21,28,29]$. The risk can be reduced at the outset by avoiding the joint use of the biologic antilymphoid agents (i.e. ALG and OKT3) with cyclosporine and tacrolimus except as a last resort, and then with extreme caution.

When PTLD is diagnosed early in development, it is usually a trivial problem requiring only drug dose reduction. At the Children's Hospital of Pittsburgh, nine (13.2\%) of 68 recipients (of 69 kidney allografts) treated with tacrolimus-based immune suppression between 1989 and 1995 developed histopathologically verified PTLD [30 •]. No deaths resulted, or any graft losses except from chronic rejection 3 years later in one case. At the same institution, histopathologically verified PTLD was diagnosed in 28 (12.1\%) of the 232 consecutive primary liver recipients treated with tacrolimus between 1989 and 1995. Although five of the 28 died of potentially PTLD-related complications, the 4-year patient and graft survival (82.2\%) is essentially the same as in the 204 non-PTLD cases.

\section{Therapeutic implications}

Understanding the concept of the donor-recipient leukocyte dialogue inherent in the two-way paradigm helps in predicting what can (and cannot) be accomplished with various toleranceinducing strategies, all of which are attempts to influence this immunologic interaction.

\section{Adjunct leukocyte infusion}

Historic efforts to improve organ transplantation results with donor-specific blood transfusion [31] or donor bone marrow [32,33] were based on sound therapeutic principles involving the unrecognized augmentation of chimerism. In an extension of these pioneer trials, our premise was that the spontaneous microchimerism of organ transplantation could be greatly augmented by the co-administration of unmodified donor bone marrow cells without a significant risk of GVH disease, providing the two immunocyte populations were initially competent and that 
immunosuppression was delivered to both equally. It also was predicted that the timing, severity, and frequency of acute rejection would be approximately the same as in non-marrow augmented control patients $[1,34,35]$.

These expectations have been fulfilled in 200 human organ recipients treated at the University of Pittsburgh [35,36••,37], including 86 who were given kidneys. The presence of donor DNA in myeloid and erythroid colonies generated from recipients' peripheral blood mononuclear cells as measured in standard [36••] or innovative clonal hematopoietic progenitor cell assays [38•] has provided unequivocal evidence of augmented stem-cell chimerism. There were no examples of significant GVH disease.

The hypotheses of therapeutic efficacy being tested are that the threat of delayed (acute or chronic) rejection can be reduced and that the frequency of ultimate drug independence can be increased by the higher persistent level of chimerism. An efficacy evaluation is expected to take 5 to 10 years $[10 \bullet \cdot 35]$, which is roughly the same time frame for tolerance induction learned from clinical experience with major histocompatibility complex-incompatible liver and bone marrow transplantation $[10 \bullet \bullet, 34]$.

\section{Hematolymphopoietic growth factors}

The use of hematopoietic growth factors is another potential chimerism-enhancing strategy that is well established in bone marrow, but not in organ, transplantation. Granulocytemacrophage colony-stimulating factor (GM-GSF), and granulocyte colony-stimulating factor are two cytokines that act at an early point in the hematopoietic cascade. The recently cloned Flt3 ligand [39] is another example. The expression of Flt3 (a member of the type III receptor tyrosine family) is believed to be restricted to primitive progenitor cells. These cells respond dramatically to Flt3 ligand [39-42], an effect that is increased synergistically by coadministration of colony-stimulating factors and $c$-kit ligand (stem-cell factor) [39-42,43•, 44].

Administration of Flt3 ligand to normal mice leads to dramatic increases in DC numbers, both in lymphoid and in nonlymphoid tissues [45]. Although DCs have been implicated historically in the induction of anti-allograft immunity, they also have tolerogenic properties [46•] and at the 'immature' precursor/progenitor stage they may be capable of subverting T-cell responses in vitro and of prolonging allograft survival $[47,48,49 \cdot \bullet]$. In contrast to the influence of Flt3 ligand, DGs in mouse lymphoid tissue are only enhanced to a moderate degree by GM-CSF $[45,50]$. Because numbers both of donor and of host hematopoietic cells of multiple lineages are increased by administration of GM-CSF, granulocyte colony-stimulating factor, and Flt3 ligand, these cytokines (particularly Flt3 ligand) may provide a pharmacologic means of enhancing organ transplant chimerism.

\section{Predictable hazards}

As with donor leukocyte infusion, such cytokine therapy is expected to be safe only if both cell populations are subject to the same conditions of immune suppression (i.e. growth factor treatment is started perioperatively). In contrast, alterations of only one of the interacting arms must be approached with caution, as exemplified by the historical experience with GVH disease after cytoablation and bone marrow transplantation. When the converse tactic of leukocyte or T-cell specific depletion of intestinal allografts was attempted as GVH disease prophylaxis in the 1980s, virtually every bowel recipient who survived the perioperative period developed lethal EBV- associated B-cell lymphomas [51].

Unbalance also can be caused by delayed provision of donor leukocytes (e.g. repeat infusion of adjunct donor bone marrow to an organ recipient). To the extent that the first exposure 
(whether to infused leukocytes or to passenger leukocytes in a transplanted organ) induces tolerance, the result of the second stage delivery can resemble the effect of a parent to defenseless offspring $F_{1}$ hybrid experiment. Investigators signing on for multicenter trials of serial bone marrow augmentation should be made aware of the consequent increased risk of GVH disease.

\title{
Xenotransplantation
}

Guidelines elucidated by the two-way paradigm will dictate strategies of xenotransplantation. The feasibility of producing stable xenogeneic chimerism has been demonstrated in pigs given unaltered primate bone marrow intravenously a few hours after birth, without any immunosuppression [52•]. Because the primary source of complement is the liver, not the hematolymphopoietic system, it is unlikely that humoral rejection caused by the interspecies complement activation will be abrogated, no matter what the duration of chimerism [52•]. However, by inducing chimerism in pigs who already have human complement regulatory proteins in their organs at birth, the barrier of complement activation and cellular tolerance may be jointly approached by clinical strategies that are discussed elsewhere [52•].

\section{Conclusion}

The assumption that stem-cell driven hematolymphopoietic chimerism was irrelevant to successful whole organ transplantation as currently practiced has led to inadequate explanations of organ allograft acceptance and clouded the meaning of successful bone marrow transplantation. This has therefore precluded the development of a central principle of transplantation. Incorporation of the chimerism factor into a two-way paradigm has allowed previous enigmas of organ as well as bone marrow engraftment to be explained and should allow key advances in basic immunology to be more meaningfully exploited in transplantation, including development of xenotransplantation.

\author{
Abbreviations \\ DC dendritic cell \\ EBV Epstein-Barr virus \\ GM-CSF granulocyte-macrophage colony-stimulating factor \\ GVH graft-versus-host \\ HVG host-versus-graft \\ PTLD post-transplant lymphoproliferative disorders
}

\section{Acknowledgments}

The work of the authors cited in this review was aided by Project Grant No. DK 29961 from the National Institute of Health, Bethesda, Maryland.

\section{References and recommended reading}

Papers of particular interest, published within the annual period of review, have been highlighted as:

- of special interest

•• of outstanding interest 
1. Starzl TE, Demetris AJ, Murase N, Ildstad S, Ricordi C, Trucco M. Cell migration, chimerism, and graft acceptance. Lancet 1992;339(1):1579-1582. [PubMed: 1351558]

2. Starzl TE, Demetris AJ, Trucco M, Murase N, Ricordi C, Ildstad S, Ramos H, Todo S, Tzakis A, Fung $\mathrm{JJ}$, et al. Cell migration and chimerism after whole organ transplantation: the basis of graft acceptance. Hepatology 1993;17:1127-1152. [PubMed: 8514264]

3. Steinman RM, Cohn ZA. Identification of a novel cell type in peripheral lymphoid organs of mice, I. Morphology, quantitation, tissue distribution. J Exp Med 1973;137:1142-1162. [PubMed: 4573839]

4. Schlitt HJ, Hundrieser J, Hisanaga M, Uthoff K, Karck M, Wahlers T, Wonigeit K, Pichlmayr R. Patterns of donor-type microchimerism after heart transplantation. Lancet 1994;343:1469-1471. [PubMed: 7911180]

5. Demetris AJ, Murase N, Fujisaki S, Fung JJ, Rao AS, Starzl TE. Hematolymphoid cell trafficking, microchimerism, and GVHD reactions after liver, bone marrow, and heart transplantation. Transplant Proc 1993;25:3337-3344. [PubMed: 7505503]

6. Qian S, Demetris AJ, Murase N, Rao AS, Fung JJ, Starzl TE. Murine liver allograft transplantation: tolerance and donor cell chimerism. Hepatology 1994;19:916-924. [PubMed: 8138266]

7. Murase N, Starzl TE, Tanabe M, Fujisaki S, Miyazawa H, Ye Q, Delaney CP, Fung JJ, Demetris AJ. Variable chimerism, graft versus host disease, and tolerance after different kinds of cell and whole organ transplantation from Lewis to Brown-Norway rats. Transplantation 1995;60:158-171. [PubMed: 7624958]

8. Starzl TE, Demetris AJ. Transplantation milestones: viewed with one- and two-way paradigms of tolerance. JAMA 1995;273:876-879. [PubMed: 7869559]

9. Przepiorka D, Thomas ED, Durham DM, Fisher L. Use of a probe to repeat sequence of the Y chromosome for detection of host cells in peripheral blood of bone marrow transplant recipients. Am J Clin Pathol 1991;95:201-206. [PubMed: 1992610]

10. Starzl TE, Demetris AJ, Murase N, Trucco M, Thomson AW, Rao AS. The lost chord: microchimerism. Immunol Today 1996;17:577-584. [PubMed: 8991290] Most complete overview on microchimerism since its discovery in 1992 in organ transplant recipients.

11. Starzl TE, Marchioro TL, Waddell WR. The reversal of rejection in human renal homografts with subsequent development of homograft tolerance. Surg Gynecol Obstet 1963;117:385-395. [PubMed: 14065716]

12. Morecki S, Leshem B, Eid A, Slavin S. Alloantigen persistence in induction and maintenance of transplantation tolerance. J Exp Med 1987;165:1468-1480. [PubMed: 3295107]

13. Bushell A, Pearson TC, Morris PJ, Wood KJ. Donor-recipient microchimerism is not required for tolerance induction following recipient pretreatment with donor-specific transfusion and anti-CD4 antibody. Transplantation 1995;59:1367-1371. [PubMed: 7770920]

14. Wood K, Sachs DH. Chimerism and transplantation tolerance: cause and effect. Immunol Today 1996;17:584-587. [PubMed: 8991291] Argument that microchimerism is an epiphenomen, rather than the cause, of organ allograft acceptance.

15. Murase N, Demetris AJ, Tsamandas AC, Ye Q, Starzl TE. The heterogenous distribution of chimerism produced by rat organ and bone marrow allotransplantation. Transplantation 1996;61:1126-1131. [PubMed: 8623200]

16. Nalesnik MA, Rao AS, Furukawa H, Pham S, Zeevi A, Fung JJ, Klein G, Gritsch A, Elder E, Whiteside TL, Starzl TE. Autologous lymphokine-activated killer (LAK) cell therapy of $\mathrm{EBV}^{+}$and EBV lymphoproliferative disorders arising in organ transplant recipients. Transplantation 1997;63:12001205. [PubMed: 9158009] The seminal role is described of microchimerism in the pathogenesis of post-transplant lymphoproliferative disorders.

17. Schwartz R, Andre-Schwartz J, Armstrong MYK, Beldotti L. Neoplastic sequelae of allogenic disease, I. Theoretical considerations and experimental design. Ann NY Acad Sci 1966;129:804821.

18. Penn I, Hammond W, Brettschneider L, Starzl TE. Malignant lymphomas in transplantation patients. Transplant Proc 1969;1:106-112. [PubMed: 4944206]

19. Starzl TE, Penn I, Putnam CW, Groth CG, Halgrimson CG. Iatrogenic alterations of immunologic surveillance in man and their influence on malignancy. Transplant Rev 1971;7:112-145. [PubMed: 4401720] 
20. Klein G, Klein E. Evolution of tumours and the impact of molecular oncology. Nature 1985;315:190195. [PubMed: 2987696]

21. Starzl TE, Nalesnik MA, Porter KA, Ho M, Iwatsuki S, Griffith BP, Rosenthal JT, Hakala TR, Shaw BW Jr, Hardesty RL, et al. Reversibility of lymphomas and lymphoproliferative lesions developing under cyclosporine-steroid therapy. Lancet 1984;1:583-587. [PubMed: 6142304]

22. Nalesnik, MA.; Makowka, L.; Starzl, TE. The diagnosis and treatment of post transplant lymphoproliferative disorders. In: Ravitch, M., editor. Current Problems in Surgery. Vol. 25. Chicago, Illinois: Year Book Medical Publishers, Inc; 1988. p. 367-472.

23. Reyes J, Zeevi A, Ramos H, Todo S, Demetris AJ, Nour B, Nalesnik M, Trucco M, Abu-Elmagd K, Fung JJ, Starzl TE. Frequent achievement of a drug-free state after orthotopic liver transplantation. Transplant Proc 1993;25:3315-3319. [PubMed: 8266556]

24. Klein G. The Epstein-Barr virus and neoplasia. N Engl J Med 1975;293:1353-1357. [PubMed: 171578]

25. Klein G. Epstein-Barr virus strategy in normal and neoplastic B cells. Cell 1994;77:791-793. [PubMed: 8004668]

26. Khanna R, Burrows SR, Moss DJ. Immune regulation in Epstein-Barr virus-associated diseases. Microbiol Rev 1995;59:387-405. [PubMed: 7565411]

27. Masucci MG. Viral immunopathology of human tumors. Curr Opin Immunol 1993;5:693-700. [PubMed: 7902103]

28. Calne RY, Rolles K, White DJG, Thiru S, Evans DB, McMaster P, Dunn DC, Craddock GN, Henderson RG, Aziz S, Lewis P. Cyclosporin A initially as the only immunosuppressant in 34 recipients of cadaveric organs: 32 kidneys, 2 pancreases, and 2 livers. Lancet 1979;ii:1033-1036. [PubMed: 91781]

29. Cox KL, Lawrence-Miyasaki LS, Garcia-Kennedy R, Lennette ET, Martinez OM, Krams SM, Berquist WE, So SKS, Esquivel CO. An increased incidence of Epstein-Barr virus infection and lymphoproliferative disorder in young children on FK506 after liver transplantation. Transplantation 1995;59:524-529. [PubMed: 7533344]

30. An account of a large experience with tacrolimus in pediatric renal transplant recipients with emphasis on their better quality of life and morbidity.

31. Salvatierra O Jr, Vincenti F, Amend WJ, Potter D, Iwaki Y, Opelz G, Terasaki P, Duca R, Cochrum $\mathrm{K}$, Hanes D, et al. Deliberate donor-specific blood transfusions prior to living related renal transplantation. A new approach. Ann Surg 1980;192:543-552. [PubMed: 6448588]

32. Monaco AP, Clark AW, Wood ML, Sahyoun Al, Codish SD, Brown RW. Possible active enhancement of human cadaver renal allograft with antilymphocyte serum (ALS) and donor bone marrow: case report of an initial attempt. Surgery 1976;79:384-392. [PubMed: 769219]

33. Barber WH, Mankin JA, Laskow DA, Dierhoi MH, Julian BA, Curtis JJ, Diethelm AG. Long term results of a controlled prospective study with transfusion of donor-specific bone marrow in 57 cadaveric renal allograft recipients. Transplantation 1991;51:70-75. [PubMed: 1987708]

34. Starzl TE, Demetris AJ, Murase N, Thomson AW, Trucco M, Ricordi C. Donor cell chimerism permitted by immunosuppressive drugs: a new view of organ transplantation. Immunol Today 1993;14:326-332. [PubMed: 8397774]

35. Fontes P, Rao A, Demetris AJ, Zeevi A, Trucco M, Carroll P, Rybka W, Ricordi C, Dodson F, Shapiro $\mathrm{R}$, et al. Augmentation with bone marrow of donor leukocyte migration for kidney, liver, heart, and pancreas islet transplantation. Lancet 1994;344:151-155. [PubMed: 7912764]

36. Rao AS, Fontes P, Dodson F, Zeevi A, Rugeles MT, Abu-Elmagd K, Aitouche A, Rosner G, Trucco M, Demetris AJ, et al. Augmentation of natural chimerism with donor bone marrow in orthotopic liver recipients. Transplant Proc 1996;28:2959-2965. [PubMed: 8908140] First proof of augmented precursor stem cell engraftment in kidney recipients given simultaneous donor bone marrow.

37. Shapiro R, Rao AS, Fontes P, Zeevi A, Jordan M, Scantlebury VP, Vivas C, Gritsch A, Corry RJ, Egidi F, et al. Combined simultaneous kidney/bone marrow transplantation. Transplantation 1995;60:1421-1425. [PubMed: 8545868]

38. Garcia Morales R, Esquenazi V, Zucker K, Gomez CI, Fuller L, Carreno M, Cirocco R, Alamo A, Karatzas T, Burke GW III, et al. Assessment of the effects of cadaver donor bone marrow on kidney allograft recipient blood cell chimerism by a novel technique combining PCR and flow cytometry 
(PCR-FLOW). Transplantation 1996;62:1149-1160. [PubMed: 8900317] The findings in 38 were verified using a novel detection technique.

39. Lyman SD, James L, Bos TV, de Vries P, Brasel K, Gliniak B, Hollingsworth LT, Picha S, McKenna $\mathrm{HJ}$, Splett RR, et al. Molecular cloning of a ligand for the flt3/flk-2 tyrosine kinase receptor: a proliferative factor for primitive hematopoietic cells. Cell 1993;75:1157-1167. [PubMed: 7505204]

40. Hannum C, Culpepper J, Campbell D, McClanahan T, Zurawski S, Bazan JF, Kastelein R, Hudak S, Wagner J, Mattson J, et al. Ligand for FLT3/FLK2 receptor tyrosine kinase regulates growth of haematopoietic stem cells and is encoded by variant RNAs. Nature 1994;368:643-648. [PubMed: 8145851]

41. Lyman SD, James L, Johnson L, Brasel K, de Vries P, Escobar SS, Downey H, Splett RR, Beckmann $\mathrm{P}, \mathrm{McKenna} H \mathrm{HJ}$. Cloning of the human homologue of the murine flt 3 ligand: a growth factor for early hematopoietic progenitor cells. Blood 1994;83:2795-2801. [PubMed: 8180375]

42. Jacobsen SEW, Okkenhaug C, Myklebust J, Veilby OP, Lyman SD. The FLT3 ligand potently and directly stimulates the growth and expansion of primitive murine bone marrow progenitor cells in vitro: synergistic interactions with interleukin (IL) 11, IL-12, and other hematopoietic growth factors. J Exp Med 1995;181:1357-1363. [PubMed: 7535335]

43. Shah AJ, Smogorzewska M, Hannum C, Crooks GM. Flt3 ligand induces proliferation of quiescent human bone marrow $\mathrm{CD} 34^{+} \mathrm{CD} 38^{-}$cells and maintains progenitor cells in vitro. Blood 1996;87:3563-3570. [PubMed: 8611678] This is the first description in humans of augmented circulating progenitor and stem cells following treatment with the most potent known hemotolymphopoietic growth factor.

44. Muench MO, Roncarolo MG, Menon S, Xu Y, Kastelein R, Zurawski S, Hannum CH, Culpepper J, Lee F, Namikawa R. FLK2/FLT-3 ligand regulates the growth of early myeloid progenitors isolated from human fetal liver. Blood 1995;85:963-972. [PubMed: 7531516]

45. Maraskovsky E, Brasel K, Teepe M, Roux ER, Lyman SD, Shortman K, McKenna HJ. Dramatic increase in the numbers of functionally mature dendritic cells in Flt3 ligand-treated mice: multiple dendritic cell subpopulations identified. J Exp Med 1996;184:1953-1962. [PubMed: 8920882]

46. Thomson AW, Lu L, Murase N, Demetris AJ, Rao AS, Starzl TE. Microchimerism, dendritic cell progenitors and transplantation tolerance. Stem Cells 1995;13:622-639. [PubMed: 8590864] Summary of experimental evidence up to early autumn 1995 that dendritic cells can be tolerogenic as well as immunogenic.

47. Lu L, McCaslin D, Starzl TE, Thomson AW. Mouse bone marrow-derived dendritic cell progenitors (NLDC $145^{+}, \mathrm{MHC}$ class $11^{+}, \mathrm{B} 7-1^{\mathrm{dim}}, \mathrm{B} 7-2^{-}$) induce alloantigen-specific hyporesponsiveness in murine T lymphocytes. Transplantation 1995;60:1539-1545. [PubMed: 8545887]

48. Rastellini C, Lu L, Ricordi C, Starzl TE, Rao AS, Thomson AW. GM-CSF stimulated hepatic dendritic cell progenitors prolong pancreatic islet allograft survival. Transplantation 1995;60:1366-1370. [PubMed: 8525540]

49. Fu F, Li Y, Qian S, Lu L, Chambers F, Starzl TE, Fung JJ, Thomson AW. Costimulatory moleculedeficient dendritic cell progenitors (MHC class $11^{+}, \mathrm{CD} 80^{\mathrm{dim}}, \mathrm{CD} 86$ ) prolong cardiac allograft survival in non-immunosuppressed recipients. Transplantation 1996;62:659-665. [PubMed: 8830833] First direct demonstration that precursor dendritic cells induce donor-specific nonreactivity to concomitant transplanted organ allografts.

50. Vremec D, Lieschke GJ, Dunn AR, Robb L, Metcalf D, Shortman K. The influence of granulocytemacrophage colony-stimulating factor on dendritic cell levels in mouse lymphoid organs. J Eur Immunol 1997;27:40-44.

51. Starzl TE, Todo S, Tzakis A, Alessiani M, Casavilla A, Abu-Elmagd K, Fung JJ. The many faces of multivisceral transplantation. Surg Gynecol Obstet 1991;172:335-344. [PubMed: 2028370]

52. StarzlTEDemetrisAJMuraseNValdiviaLThomsonAWFungJRaoASThe future of transplantation: with particular reference to chimerismi and xenotransplantation. Transplant Proc199729M1927 [PubMed: 9122957] Emphasizes the necessity of establishing chimerism if xenotransplantation is to be made feasible. 


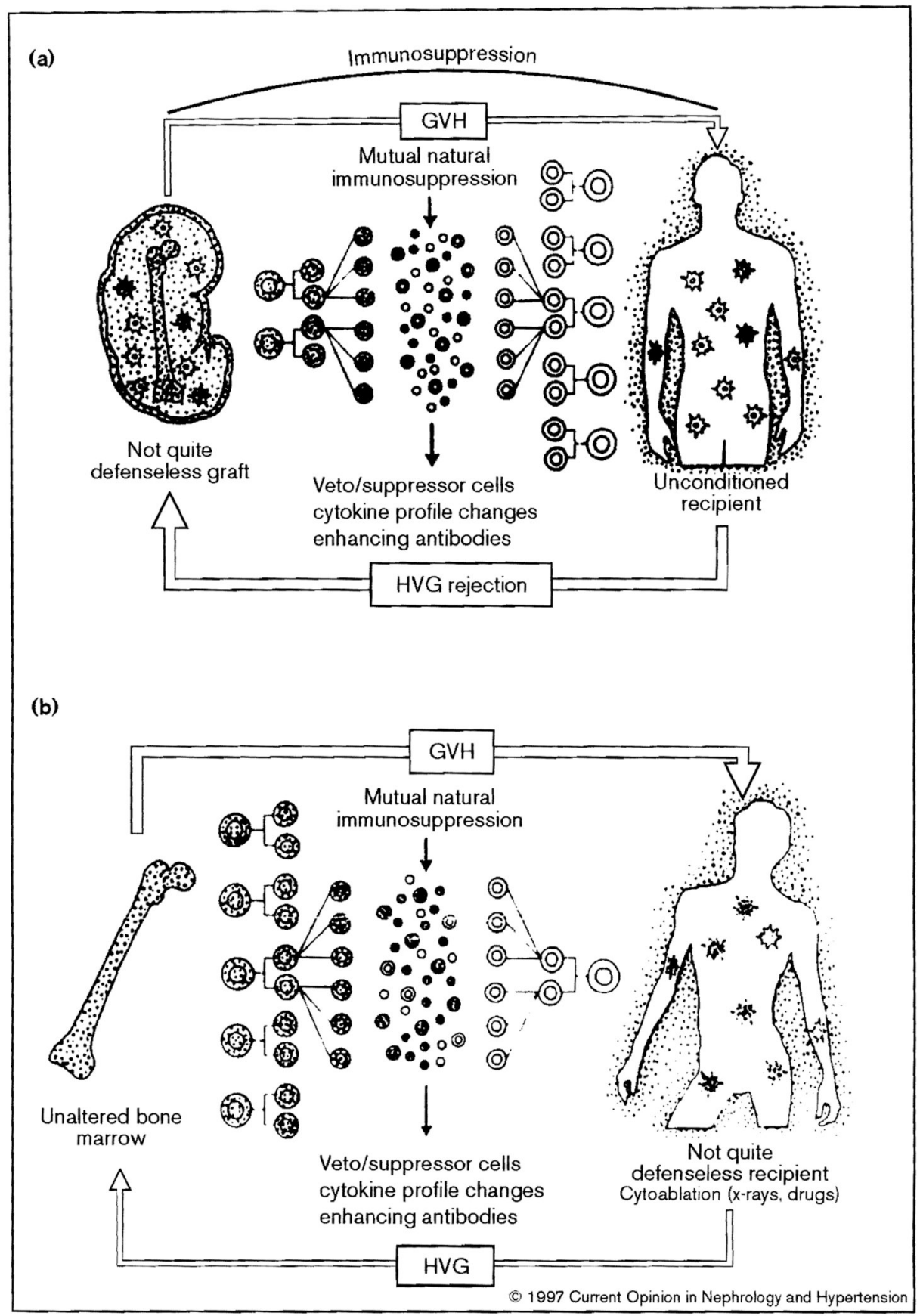

Figure 1.

Two-way paradigm with which transplantation is seen as a bidirectional and mutually cancelling immune reaction that is (a) predominantly host-versus-graft (HVG) with whole organ grafts, and (b) predominantly graft-versus-host $(\mathrm{GVH})$ with bone marrow grafts. 


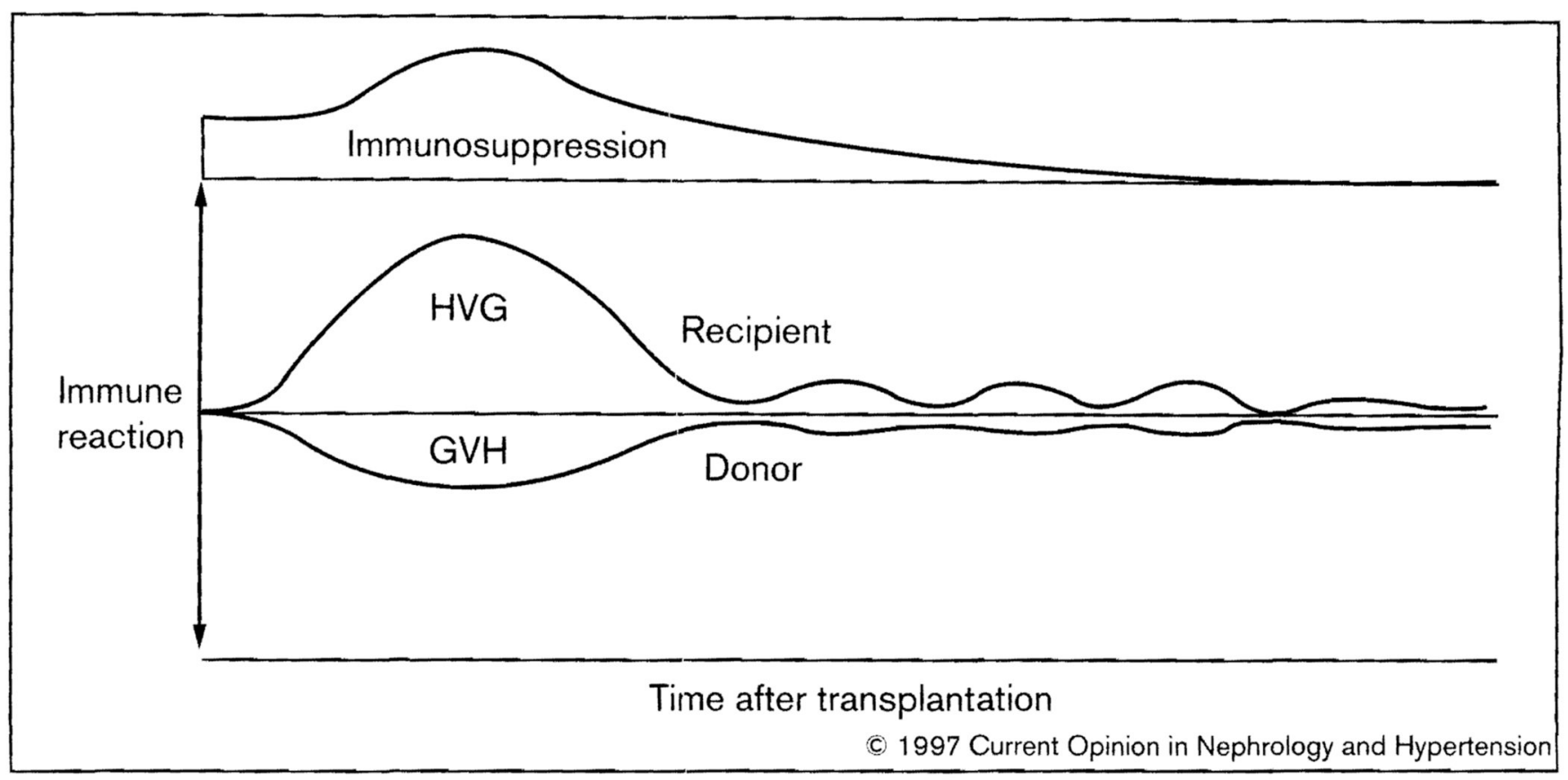

Fig. 2.

Contemporaneous host-versus-graft (HVG) and graft-versus-host (GVH) reactions in the twoway paradigm of transplantation immunology. After the initial interaction, the evolution of nonreactivity of each leukocyte population to the other is seen as a predominantly low-grade stimulatory state that may wax and wane, rather than a deletional one. 
Table 1

Differences between conventional bone marrow and organ transplantation

\begin{tabular}{lll}
\hline & Bone Marrow & Organ \\
\hline Recipient cytoablation & Yes & No \\
MHC compatibility & Critical & Not critical \\
Principal complication & GVHD & Rejection \\
Drug free state & Common & Rare \\
Term for success & Tolerance & 'Acceptance, ** \\
\hline
\end{tabular}

* AII differences derive from this therapeutic step, which in effect establishes an unopposed graft-versus-host (GVH) reaction in the bone marrow recipient whose countervailing immune reaction is eliminated. $* *$

or 'operational tolerance'. GVHD, graft-versus-host disease; MHC, major histocompatibility complex. 